\title{
Conceptual metaphors in lyrics, vocal realization and music - reinforcement or modification of emotional potential
}

\begin{abstract}
The paper seeks to examine the ways in which the emotional potential (germ. Emotionspotential) rooted in the textual part of selected songs can potentially be reinforced or modified by the music and vocal realization. Music and intonation provide sonic counterparts of the emotional states expressed by language. I shall consider cases where the sonic counterpart is either an analog or stands in contrast to the textual component and the affective value commonly associated with the invoked conceptual metaphor/metonymy. The research material consists of three versions of the song Ride by 21 Pilots, the song Here Comes the Night Time by Arcade Fire and Die Flut [the flood] by Joachim Witt and Peter Heppner. The analysis results show that salient presence of UP/DOWN image schema in verbal and musical orientational metaphors is observable, albeit not always accompanied with the most typical valence pattern.
\end{abstract}

Keywords: cognitive linguistics, conceptual metaphors, emotions, melody and lyrics, popular music.

\section{Introduction}

The aim of the paper is to examine the emotional potential (Germ. Emotionspotential; cf. Schwarz-Friesel 2007: 212) emerging in selected songs as a result of an interplay of image schemata, conceptual metaphors/metonymies and emotionally laden lexemes or language units. The schemata, metaphors and metonymies in the songs are evoked by lyrics, vocal realization and music. Thus, it is assumed that the emergent structure of meaning is created not only by linguistic but also by aural constructions, i.e. the musical component and the particular act of vocal performance by which the emotional potential contained in the text may be either reinforced of modified. With respect to the non-linguistic component, this paper focuses mainly on melody

1 Address for correspondence: Institute of Linguistics, University of Szczecin, al. Piastów 4b, bud.5, pok. 104, 71-065 Szczecin, Poland. E-mail: magdalena.zyga@usz.edu.pl 
and intonation, understood as the sequence of pitches produced by a singer as indicated by the composer (cf. Shrivastav \& Wingate 2008: 71). Note that, to arrive at the overall meaning or interpretation of a given song, both cognitive and affective information need to considered (cf. Sopory 2005: 452, 454). The goal of the analysis presented here is to offer possible interpretations and hypotheses rather than to offer final indisputable explanations since, as noted by Morini (2013), analyses of multimodal constructs such as songs are often fraught with an inevitable degree of impressionism due to imprecision as a feature of musical meaning (cf. 2013: 290).

\section{Emotions, music and metaphor}

When discussing the affect or affective value and interplay between emotion, metaphor and music, one needs to clarify which concepts and definitions are drawn upon, because various terms and divergent definitions (even when the same term is used) can be found in the literature on the subject. The scholar who needs to be mentioned here with respect to the content and structure of emotion concepts as revealed by metaphors and metonymy is Kövecses (1990). Further, Juslin and Sloboda (2010) offered coverage of the numerous approaches defining the field of music and emotion, and Zbikowski (2017a) elaborated on the issue of how musical utterances are constructed and used to communicate meaning.

In this paper, we rely upon the terms concerning affect and their understanding as provided by Schwarz-Friesel (2007: 2015). She differentiates between feelings (germ. Gefühle), emotions (germ. Emotionen) and, with regard to texts, emotional potential (germ. Emotionspotential). According to Schwarz-Friesel (2007, 2015), feelings are these aspects of emotions of which people are aware and experience introspectively, whereas emotions are to be treated as a broader phenomenon, encompassing feelings but with an addition of unconscious effects. Emotions include not only conscious but also unconscious knowledge, representations and processes and physical, mental and affective conditions (cf. Schwarz-Friesel 2007: 55, 102; Schwarz-Friesel 2015: 293). Hence, feelings can be perceived as discrete units that can be named, and emotions can be mixed and referred to, more generally, as being positive or negative, perhaps with details expressed verbally in a more descriptive way. Emotional potential, in turn, is an inherent feature of any text that is rooted in its information structure, coherence and implicit information determined by the text's referential and inferential potential (cf. SchwarzFriesel 2015: 167). The constituent potential in the term's name suggests that emotional potential is something that can be either activated or not. In the case of song lyrics, music or vocal intonation can be a triggering factor.

The music accompanying lyrics provides sonic counterparts that can be analogs (cf. Zbikowski 2009: 363) or opposites of the dynamic processes or emotional states expressed by the language. In contrast to Zbikowski (2009), the focus of this paper is not 
only on mapping the concepts expressed by the text onto sequences of music, such as the descending sounds matching the words denoting downward movement (also used as evaluative terms) (cf. Zbikowski 2009: 360, 366 et passim), but I shall also consider cases when the sonic counterpart stands in contrast, or as if in contrast, to the verbal utterance and the affective value commonly ascribed to the evoked conceptual metaphor.

The image schema that plays a crucial role in structuring not only verbal metaphors but also metaphors which are manifested via the musical mode is the UP/DOWN schema, also known as the VERTICALITY schema (cf. Górska 2014: 180-181). With respect to music Zbikowski notices, "the common construal of musical pitches as situated in vertical space, a construal that follows from the characterization of pitches as 'high' or 'low' with respect to one another" (2009: 360). This perception provides motivation for the metaphor PITCH RELATIONSHIPS ARE RELATIONSHIPS IN VERTICAL SPACE (cf. Górska 2014: 185). Moreover, typically, the UP orientation is associated with positive experiences, while the Down orientation is associated with negative ones, which gives rise to pairs of conceptual metaphors with a positive and negative valence attached to them, respectively (cf. Górska 2014: 182; Sopory 2005: 442). Hence, we have widespread orientational metaphors such as HAPPY IS UP - SAD IS DOWN, HAVING CONTROL/FORCE IS UP - BEING SUBJECT TO CONTROL/FORCE IS DOWN, (cf. Górska 2014: 182) or the more general GOOD or POSITIVE IS UP and BAD or NEGATIVE IS DOWN (cf. Sopory 2005: 442).

In the light of the above, it can be observed, following Zbikowski (cf. 2009: 366), that the mapping from the domain of text onto the domain of music makes us perceive music in a particular way. For verbo-musical metaphors, however, the opposite is also true: the music guides the recipient's understanding of the text, e.g. the descending sounds matching - as sonic analogs - the words denoting downward movement (cf. Zbikowski 2009: 366). This is also valid if the words and sonic analogs evoke the verticality schema connected with the orientational metaphors invoking emotions (cf. Zbikowski 2017b: 507). Furthermore, musical metonymy can play a part in the activation of emotional potential of a musical composition since, for example, an opening motto of a symphony can serve as a part which guides the understanding through its connection to the larger whole (cf. Zbikowski 2018: 14). Nevertheless, one should be careful when identifying and ascribing affective value to a given fragment of text or music or manner of vocal performance in a song. The risk consists, on the one hand, in identifying the conceptual metaphor evoked by the non-linguistic component and, on the other hand, in taking into account solely or focussing mainly on the valence scale rather than on both scales of a two-dimensional emotion model by valence and arousal when ascribing the affective value to a given musical metaphor. These issues are addressed by Sopory (2005) and, rather indirectly, by Kim and Andre (2008) in their papers.

Sopory (2005) noticed that certain conceptual metaphors evoked by language expressions are typically attached to certain valence patterns. MORE IS UP, for instance, 
is typically associated with positive valence on the basis of the experience of accumulation (having more of something rather than less) and rising (in contrast to falling) and affective information connected with such experience, which evokes the widespread metaphor POSITIVE IS UP. In the case of the sentence Prices are skyrocketing again, however, the default valence attached to the UP/DOWN schema is overridden on the basis of our experiential knowledge, i.e. that an increase in prices is a negative phenomenon (cf. Sopory 2005: 442). Thus, the typically ensuing metaphor PosITIVE IS UP rather than the more general MORE IS UP is not the valid one here. The two-dimensional emotion model by valence and arousal (Fig. 1) used in an experiment by Kim and Andre (2008), in turn, begets reflection on the fact that the arousal scale is not to be overlooked when interpreting affective value conveyed or evoked by music. Fig. 2 (Kim \& Andre 2008: 5) depicts on the musical emotion model the relevant musical features of songs selected by the study participants. The cues for the selection of four songs to correspond to the four quadrants of the emotion model were: song 1 - positively exciting, energizing, joyful, exuberant; song 2 - noisy, loud, irritating, discord; song 3 - melancholic, sad memory; and song 4 - blissful, pleasurable, slumberous, tender (cf. Kim \& Andre 2008: 5). The quoted figure reflecting the participants' song selection to prepare the setting of the experiment in which the subjects' physiological responses corresponding to emotions were measured suggests that the same values of some song parameters, such as volume, pitch or tempo, may be indicative of the same type of arousal while evoking different valences (either positive or negative). It can be observed, for instance, that high pitch seems to be predominantly associated with high arousal, but it could also correspond to either a positive (which is more likely) or negative valence. By the same token, a fast and slow tempo, apparently mostly indicative of high and low arousal, respectively, may be valued positively or negatively in terms of valence. It should be borne in mind as well that, as Kim and Andre aptly noticed, "[e]motional responses to music vary greatly from individual to individual, depending on their unique past experiences" (Kim \& Andre 2008: 5).

Another study concerning language, image schemata and evaluative components whose results are relevant for the analysis presented here is Beate Hampe's (2005) analysis of semantically highly redundant verb-particle constructions. The researcher focuses on the phrasal verb pairs finish up/finish off and slow up/slow down to verify or falsify Krzeszowski's (1997) proposal concerning the axiological relevance of the image schemata, such as UP/DOWN, FRONT/BACK, RIGHT/LEFT, and NEAR/FAR, where in each pair the elements carry opposing axiological defaults with the first element being positively and the second negatively charged (cf. Krzeszowski 1997: 112-131; Hampe 2005: 120-121). This plus-minus parameter is supposed to be a property of image schemata. Furthermore, Krzeszowski claimed that "metaphorization reinforces the axiological charge of concepts or activates latent axiological charge" (Krzeszowski 
1997: 156). The results of Hampe's (2005) study of corpus data showing the real usage of the four phrasal verbs did not confirm any predictions as to the evaluative value of the items made on the basis of the plus-minus parameter postulate. She is also of opinion that the earlier study by Lewandowska-Tomaszczyk and Hanks (1996) of verbs with and without particles, such as block (up/off), finish (up/off), and close (up/down), which is said to confirm the plus-minus assumption, can actually be seen as leading to a rejection of this assumption. The researchers conceived of the plus-minus parameter as a context-sensitive device, where "the prototypical default values can be changed by the elements in the context" (Lewandowska-Tomaszczyk \& Hanks 1996: 92), which is not stated or implied in the original claim by Krzeszowski (1997). Hampe concluded that isolated ("primitive") image schemata should in fact not be "considered as the locus of evaluative defaults" (Hampe 2005: 115), but the positive or negative charge is rather to be viewed as a dimension of image-schema compounds that are parts of contextualized cognitive models (cf. Hampe 2005: 141). It is important to note that when a given linguistic expression is used in different contexts, even if it refers to the same conceptualization from a specific domain, it may carry different evaluative properties due to the context of its use (cf. Hampe 2005: 141).

\section{The method and material}

The method of conduct in the analysis is as follows: first, emotionally laden items and their affective charge are identified in the lyrics, and conceptual metaphors are searched for in the text. However, because evaluation is a matter of entire contexts rather than lexemes (or other items) in isolation, the surrounding words/phrases will be taken into consideration, as "lexical items may tend to occur in the company of word/phrases which are themselves predominantly (and overtly) positive or negative in their orientation" (Hampe 2005: 122). Thus, in contrast to Neary (2019), song lyrics are to be analysed separately as a departure point and not only as a last step to identify how the words interact with the melody. On the basis of lyrics analysis, some predictions are made with respect to the intonation (rising, falling, non-final) used in the act of vocal performance and to music (pitch, tempo). Subsequently, the accompanying music and vocal realization, intonation in particular, is to be examined for the presence of conceptual metaphors/metonymies, as proposed by Zbikowski (2009), and their compatibility with the items present in the lyrics, especially concerning the affective value, is assessed. To investigate the affective aspect and its role in the activation and possibly modification of the emotional potential of a given piece, I refer to a two-dimensional emotional model by valence and arousal, since the two scales (valence and arousal) make it possible to avoid discrete labels or words denoting concrete emotions and to take into consideration blended emotions (cf. Kim \& Andre 2008: 4-5). In other words, if the orientational metaphors present in the accompanying music 
and vocal realization stand in contrast with respect to the affective value (valence) assumed to be communicated through the lyrics, the aspect of arousal is to be considered as possibly explaining the dissonance (e.g. high pitch and rising intonation accompanying pessimistic line in the lyrics). If the contrast cannot be attributed to the arousal component, then possible intentional modification of emotional potential may be suggested. Limitations with regard to the possibilities of melody shaping and rhythmical regularities can account for the lyrics-music dissonance as well.

The research material consists of three versions of the song Ride by the band 21 Pilots (21P), namely the original version; the acoustic version performed by Tyler Joseph (TJ), the band's lead singer; and the a capella version by Pentatonix. The research also examines the songs Here Comes the Night Time and Creature Comfort by Arcade Fire and Die Flut [the flood] by Joachim Witt and Peter Heppner. Particularly, the divergent performances of the song Ride reveal the salient role of the interplay of the lyrics and the non-linguistic sonic counterparts with their affective charge in shaping the overall emotional potential of a song.

\section{The analysis: Ride}

\subsection{The lyrics}

With respect to the content expressed in the lyrics, the speaker in the song talks about his unrealized fantasies of suicide, which he seems to strive to resist. As a result, the emotional potential of the song seems to have both negative and positive aspects that can be activated or reinforced by the non-linguistic component. The facts that the first line, "I just wanna stay in the sun" (twenty one pilots 2015) is clearly positively charged and that the line does not finish at the end of the sentence (with "where I find") makes the recipient expect rising (in accordance with the metaphor POSITIVE IS UP) or at least non-final intonation, possibly a high pitch. In the third line, which logically finishes the sentence, "Pieces of peace in the sun's peace of mind" (twenty one pilots 2015), the intonation should also rise. The line "I know it's hard sometimes" (twenty one pilots 2015), in contrast, would harmonize with falling intonation (NEGATIVE IS DOWN). The second half of the first stanza, "Yeah, I think about the end just way too much / But it's fun to fantasize / All my enemies who wouldn't wish who I was / But it's fun to fantasize" (twenty one pilots 2015) reveals a mixture of negative and positive affects in the song's emotional potential, owing to which the anticipation regarding orientational metaphors may vary. "The end" mentioned in the first line about which the speaker thinks "way too much", together with the notion of taking his time on a ride in the chorus, can be evocative of the conceptual metaphor LIFE IS A JOURNEY with the entailment DEATH IS AT THE END OF A JOURNEY/DEPARTURE. The phrase "too much", however, may alternatively signal the metaphor MORE IS UP. Therefore, either falling 
or rising intonation might be selected for the vocal performance. The following and the closing line about fantasizing seem, at first glance, to be clearly positively loaded, while the line about the enemies seems to indicate a negative valence; hence, the expected intonation would be rising and falling, respectively. If one considers the whole context, in which fantasizing is clearly about death, the line may be sung with falling intonation.

The chorus consists of the line "I'm falling so I'm taking my time on my ride" (twenty one pilots 2015) repeated twice and followed by the sentence part "Taking my time on my ride" (twenty one pilots 2015). The notion of downward movement (falling) invites the NEGATIVE IS DOWN metaphor in the melody/vocal realization. The entire second stanza generally communicates negative affective information, so the recipient can expect the NEGATIVE IS DOWN metaphor in vocal realization. The only exception could potentially be the last two lines line in the sequence: "A bullet for them / A bullet for you / A bullet for everybody in this room / But I don't seem to see many bullets coming through / See many bullets coming through" (twenty one pilots 2015). In this case, rising intonation might be applied. With respect to the last three lines in the second stanza, neutral, affectively non-marked intonation for: "Who would you live for? / Who would you die for? / Would you ever kill?" (twenty one pilots 2015) would be the falling one for the first and the second, and the rising one for the third. To express the negative charge present in their content, the performer could, however, use falling intonation. The bridge consists of the lines "I've been thinking too much" and "Help me", where the former can be viewed as being clearly linked to "I think about the end just way too much" from the first stanza. Consequently, for both lines, falling intonation might be predicted or alternatively rising intonation for the former in consistency with the metaphor MORE IS UP, which can be evoked by "too much". For the latter, additionally mapping an INCREASE IN VOLUME onto an INCREASE IN INTENSITY (OF EMOTIONS) in vocal realization is plausible as well.

\subsection{Pilots - the original version}

The musical opening of the song can be considered metonymic in its role, since it seems to guide the recipient's perception of the piece as a whole. The version by 21 Pilots appears as energetic and joyful due to its fast, upbeat tempo (150 beats per minute) and ascending musical sequences. The first half of the first stanza seems to confirm the predictions regarding vocal realization: the intonation pertinent to the first line is rising and for the third line is rising/non-final, while for the second and fourth (which are identical) the intonation is falling. In the second half, the intonation for the fifth and seventh line, which voices concerns regarding thinking too much about death, is falling according to expectations about the affective value. Lines 6 and 8 (again identical like 2 and 4), however, draw the recipient's attention by a rather interesting interplay of language, vocal intonation and volume. The former line about fantasizing about 
death, namely, is performed with falling intonation, whereas the lexeme "fantasize", sung for the second time, is strongly emphasised and marked with rising intonation. This results in a disruption of the stanza's melodic pattern where in the first half every other line has the same intonation (i.e. lines 1 and 3 rising/non-final, 2 and 4 falling). Such a deliberate pattern breach may suggest irony, indecisiveness or may be aimed at activating not only the negative but also the positive emotional potential inherent in the stanza. Rising intonation combined with a strong emphasis on "fantasize", i.e. singing the word louder, may, alternatively, communicate high arousal and the conceptual metaphor IMPORTANCE IS VOLUME entailing (MORE) IMPORTANT IS LOUD(ER).

Once more, mixed affective information seems to be communicated in the chorus. Rising intonation is used only when the line is sung for the first time, and falling intonation is applied later. In the context of suicidal thoughts and depression expressed by the idea of falling, which can be a manifestation of NEGATIVE IS DOWN, falling intonation may be expected. The rising intonation accompanying the phrase "taking my time on my ride" (twenty one pilots 2015) evoking the LIFE IS A JOURNEY metaphor may highlight the aspect of delaying death. Such a shift of focus to life could then activate the positive emotional potential of the text. Additionally, the 'elongation' in the vocal performance of the lexeme ride thus echoing the preceding "taking my time" emphasizes the duration of the event (THE DURATION OF ACTION/EVENT IS DURATION OF ARTICULATION).

The entire second stanza is generally sung (rapped) quickly without changes in intonation. There are only short pauses at the end of the lines "But I don't seem to see many bullets coming through / See many bullets coming through" (twenty one pilots 2015), but the intonation can be still classified as non-final rather than falling, and definitely not rising, which might seem a plausible option when focusing on the text alone. Also, the question lines are sung in rapid succession such that there is no rise or fall in intonation between the questions; in other words, the two first questions finish with non-final intonation, and the intonation at the end of the last question closing the whole stanza is falling. This coincides with the fact that the lexeme kill is negatively marked, and thus its affective value may seem reinforced with the vocal intonation used. Otherwise, rising intonation is common for English yes-no questions.

Alternate high and low pitches applied with the phrase too much in the line "I've been thinking too much" is repeated four times, which functions as a bridge - musically with a slower, no longer upbeat tempo - after the chorus following the second stanza seems to invoke the VERTICALITY schema with its typical valence pattern (POSITIVE IS UP and NEGATIVE IS DOWN) to express what is commonly described as mixed feelings or possibly indecisiveness or irony on the part of the speaker. Moreover, the lines are sung in a significantly higher key, possibly to mark the importance and/or high arousal, and they are followed by the line "Help me" (twenty one pilots 2015) sung in lower key with the second word sung lower than the first, which is accompanied by a falling 
musical sequence. The succeeding lines in the original version can be divided into pairs where the first item is performed in a higher key with rising intonation by either backing vocalists or the leading vocalist but with a computer-modified voice, and the second item is sung in a lower key with falling intonation ("Help me" performed in the manner described above) by the leading vocalist:

"I've been thinking too much [high key, rising intonation] / (I've been thinking too much)

[lower key, falling intonation]

I've been thinking too much [high key, rising] / (Help me) [lower key, falling]

I've been thinking too much [high key, rising] / (I've been thinking too much) [lower key, falling]

I've been thinking too much [high key, rising]" (twenty one pilots 2015).

This mode of vocal performance seems to corroborate the hypothesis about the alternate activation of the different emotional potential of the text (positive and negative valence) by intentionally employing the UP/DOWN schema in the manner of vocal performance.

The way the chorus is sung for the last time differs significantly in terms of volume and intonation from its performance earlier in the song. The second line is articulated more loudly or even shouted out (IMPORTANCE IS VOLUME) and is shortened to "I'm taking my time" (twenty one pilots 2015) rather than "I'm taking my time on my ride". Moreover, the lexeme time is 'stretched in time', sung longer than earlier, most probably to emphasise the duration in accordance with the metaphor THE DURATION OF ACTION/EVENT IS DURATION OF ARTICULATION. The lexeme ride (signalling the LIFE IS A JOURNEY metaphor) in the last line is also articulated longer with non-final intonation. This might suggest that the death by suicide fantasized about by the speaker is to be significantly delayed or even not materialize at all.

The original version is the only one to continue beyond the last chorus. First, the line "I'm falling so I'm taking my time on my ride" (twenty one pilots 2015) is repeated twice, the second time with rising intonation and without the final lexeme ride. Subsequently, the song continues with the bridge lines (1) "I've been thinking too much" articulated by the leading vocalist, always with falling intonation or by the second voice (either backing vocalists or computer-modified voice of the leading vocalist) with rising intonation and a higher key, and (2) "Help me" articulated by the leading vocalist with falling intonation (falling sequence as described above), thereby creating a pattern:

"I've been thinking too much [falling] / Help me [ ${ }^{-}$]

I've been thinking too much [falling] / Help me [ - $\left.{ }_{-}^{-}\right]$

I've been thinking too much [rising] / I've been thinking too much [falling] 
I've been thinking too much [rising] / Help me [ - $]$

I've been thinking too much [rising] / I've been thinking too much [falling]

I've been thinking too much [rising]) / Help me [- ]" (twenty one pilots 2015).

The alternate use of rising and falling intonation, higher and lower keys and two types of voices yet again activates both negative and positive aspects of the emotional potential inherent in the verbal component of the piece, which seems to serve to express 'mixed feelings', indecisiveness or irony/sarcasm as a conclusion of the song.

\subsection{Tyler Joseph - the acoustic piano version}

The version by Tyler Joseph (BBC Radio 1, 2018), though significantly slower and on the whole sung in the lowest key of all the three versions analysed here, also starts with ascending sequences of music, making the recipient likely to expect something optimistic to follow. The first half of the first stanza is performed in the same way as the original version, i.e. the optimistic lines 1 and 3 are sung with rising intonation, while the intonation for lines 2 and 4 is falling. In contrast to the original version, the second half of the stanza is performed according to the same intonation pattern as the first half, i.e. "Yeah, I think about the end just way too much [rising] / But it's fun to fantasize [falling] / All my enemies who wouldn't wish who I was [rising] / But it's fun to fantasize [falling]" (BBC Radio 1, 2018). Such vocal realization contradicts the expectations regarding the affective value (valence) communicated via the non-linguistic component in the fifth and seventh lines. One explanation for the rising intonation of "too much" can be the wish to signal the metaphor MORE IS UP and the state of high arousal, not necessarily positive valence. Alternatively, this may suggest irony or indecisiveness. Even if such modification of the emotional potential might be perceived by listeners (which would have to be confirmed in a broader quantitative study), the easiest explanation for the employed intonation is the intention to maintain the pattern present in the first half of the stanza (rising - falling - rising - falling).

In the chorus, for which falling intonation was initially predicted based on the text examination and for which first rising and then falling intonation are applied in 21P, in this acoustic version the intonation is consistently rising. This may be accounted for, as mentioned above, by the intention to highlight the aspect of delaying death: "taking my time on my ride" (BBC Radio 1, 2018). Hence, a consistent and logical pattern of valence seems to be communicated here by the non-linguistic song component.

In the whole second stanza up to the three final questions, just as in the original version, the lines are sung so quickly one after another that there is no rise or fall in the intonation between them. With respect to the questions, the acoustic performance reveals standard, affectively non-marked falling (two first questions) and rising (the last question) intonation, whereby the final lexeme kill seems to be articulated louder, 
hence possibly drawing on the metaphor IMPORTANCE IS VOLUME. Tyler Joseph sings the bridge lines "I've been thinking too much" four times and the subsequent "Help me" with falling intonation, as anticipated on the basis of the preliminary text analysis. As for the leading voice-second voice pair, however, the parts performed by the second voice (backing vocalists or modified voice of the leading vocalist) in the original version are those which remain, albeit with the intonation changed from rising in the original version to non-final intonation, while the lines sung by the leading vocalist are deleted. Thus, the affective pattern of $21 \mathrm{P}$ seems to be changed into a predictable 'pessimistic' one - relatively low arousal, negative valence.

The manner in which the chorus is performed for the last time, again similarly to $21 \mathrm{P}$, differs in terms of volume and intonation from its performance earlier after the first and the second stanzas. In the acoustic piano version, the first verse is performed more quietly, three times and in a significantly higher key. The subsequent lines are sung in a lower key and slightly lower volume, with rise-fall intonation and the intonation clearly falling on the lexeme ride in the final line. The high pitch used for the first line together with the falling intonation employed later and concluding the piece with an additional line "Help me" (same falling intonation) (BBC Radio 1, 2018) appear to produce a rather atypical affective pattern. The high-pitched voice in this instance is apparently aimed at indicating high arousal rather than evoking the positive valence commonly attributed to the upward orientation in the VERTICALITY schema. This mode of performance might also serve to draw the recipients' attention, since this provides contrast to the rest of the song and stands in line with the metaphor IMPORTANT IS UP. As regards the co-occurring decrease in volume, such a manoeuvre may be incompatible with the conceptual mapping of IMPORTANCE onto VOLUME, but it is possible that this mode of performance results from the physical limitations of the leading vocalist's articulatory capacity. The following change to a lower key, metaphorically representing downward movement typically activating the NEGATIVE IS DOWN negative-valence metaphor, combined with falling intonation and relatively slow tempo, may be indicative of anxiety or sadness (cf. Kim \& Andre 2008: 5, Fig. 2).

\subsection{Pentatonix - the a capella cover}

In the Pentatonix a capella cover, in contrast to $21 \mathrm{P}$ and $\mathrm{TJ}$, an extra opening and closing line "I'm falling" (NOVA FM 2016) is added, sung in falling intonation with the ultimate word "falling" repeated three times, each time with a lower pitch, thus creating a descending melodic sequence. Consequently, in terms of affective value, the metonymical opening seems to relate to the VERTICALITY schema and the typical pattern of valence, which results in the activation of the conceptual metaphor NEGATIVE IS DOWN. Additionally, the tempo of the piece is significantly slower than that of the original version, which, according to Fig. 2 provided by Kim and Andre (2008: 
5), may indicate low arousal. When the overall content of the text is taken into account, Pentatonix's interpretation and the intentional activation of negative emotional potential of the text by the melodic aspect, among other things by the negative 'framing' in the form of the song's intro and outro, seems legitimate. While the intonation pattern in the first half of the first stanza is, according to expectations drawn from the text analysis, the same as in the original version, i.e. rising - falling - rising/non-final - falling, in the second half of the stanza the intonation is consistently falling for all lines, also in accordance with preliminary predictions.

For the chorus, somewhat contrary to expectations resulting from the notion of falling present in the lyrics, the rising intonation is selected. This, however, as mentioned above, can be attributed to the intention of shifting the focus to the aspect of delaying death, which is also reflected in the 'elongation' in the vocal performance of the lexeme ride, thus echoing the preceding "taking my time" to emphasize the duration of the event (THE DURATION OF ACTION/EVENT IS DURATION OF ARTICULATION) (cf. NOVA FM 2016). In this way, the positive emotional potential of the piece may be activated.

The performance of the second stanza up to the final three questions is similar to $21 \mathrm{P}$ and TJ, apart from the lines "But I don't seem to see many bullets coming through / See many bullets coming through" (NOVA FM 2016), for which, as anticipated after the text examination, rising intonation is applied. For the first two questions "Who would you live for? / Who would you die for?" (NOVA FM 2016) Pentatonix employs the rising intonation and deletes the last one about killing altogether, thereby apparently imbuing the lyrics with positive emotions.

In the bridge after the chorus following the second stanza, for the line "I've been thinking too much", which is repeated four times, alternate high and low pitches are used. This seems to invoke the VERTICALITY schema with its typical pattern of valence (POSITIVE IS UP AND NEGATIVE IS DOWN) to express what is commonly described as mixed feelings or possibly to imply indecisiveness or irony. The line "Help me" is omitted by Pentatonix in their cover. Moreover, in the succeeding lines, which in the original version can be divided into pairs, the parts performed by the leading vocalist are deleted:

"I've been thinking too much [high key, rising intonation] / (I've been thinking too much) [lower key, falling intonation]

I've been thinking too much [high key, rising] / (Help me) [lower key, falling]

I've been thinking too much [high key, rising] / (I've been thinking too much) (lower key, falling]

I've been thinking too much [high key, rising]" (NOVA FM 2016). 
This modification seems to convert the 'mixed-feelings' pattern into an 'optimistic' pattern. Albeit the intentionality of this interpretation can be corroborated by the alteration in terms of intonation earlier in the second stanza (mentioned above), it should be borne in mind that the rising intonation selected for these lines may form the activation of the MORE IS UP metaphor signalled by the phrase too much.

In contrast to the original version and the version by Tyler Joseph, Pentatonix performs the chorus for the last time the same as earlier in the piece, with the leading vocalist reaching even higher tones - possibly for dramatic effect and to impress with the vocal prowess - when singing the lexeme ride and using rising intonation in all the lines. This manoeuvre seems to, as mentioned above, activate the positive aspect of the emotional potential of the text, i.e. postponing or cancelling death (i.e. taking time on the ride) and not (the thoughts of) death (metaphorically expressed as falling). As a contrast to this part, however, an additional closing line - identical to the opening line - "I'm falling" (NOVA FM 2016) is added and is sung with falling intonation with the ultimate word falling repeated three times, each time with a lower pitch, thus creating a descending melodic sequence.

\subsection{The three versions - a comparison}

When the three versions of the song Ride are compared, some significant differences are observable, which may have an impact on the emotional potential of the piece. The most conspicuous feature of the song is creative play with the UP/DOWN conceptual schema and orientational metaphors with respect to non-linguistic components, especially in the original version. Even though the musical upbeat, fast tempo intro of the song initially metonymically guides the recipient to anticipate a piece with optimistic affective information, 21 Pilots uses alternate high and low intonation, sometimes alternately high and low voices, when singing the same textual material, e.g. the bridge line "I've been thinking too much" (twenty one pilots 2015), which can be interpreted as intentionally striving to ascribe varying affective value with respect to valence to communicate indecisiveness or irony/sarcasm. By drawing on the VERTICALITY schema with respect to pitch and intonation, in the course of the song both negative and positive aspects of emotional potential inherent in the linguistic component of the piece can be perceived as activated.

Pentatonix, in contrast, in spite of a specific 'down-framing' by means of the opening and closing line "I'm falling, falling, falling" (NOVA FM 2016) and the accompanying descending musical sequence, use rising intonation and high pitch more often and more consistently than 21 Pilots in their original version. This, together with deleting some information concerning death and requesting help from the textual component, i.e. omission of the lines "Would you ever kill?" (twenty one pilots 2015) from the second 
stanza and "Help me" (twenty one pilots 2015) from the bridge, results in prevalent activation of positive, optimistic aspects of the song's emotional potential.

The acoustic piano version by Tyler Joseph, in turn, with its slow tempo, prevalent low key and mostly falling intonation can be described in terms of affective information as a 'downer', both in terms of valence and arousal. In this context, the high-pitched line of the last chorus sung three times in a significantly higher key comes as a surprise, but this apparently intentional manoeuvre can still be interpreted as supporting, or not denying, the overall negative, pessimistic aspect of the piece's emotional potential in that it, on the one hand, allows the performer a vocal downward motion invoking the NEGATIVE IS DOWN metaphor and, on the other hand, may be evocative of a different metaphor, (MORE) IMPORTANT IS UP.

The a capella cover by Pentatonix regarding the vocal realization generally seems the most predictable one, since the intonation for almost all the lines could be anticipated based on the text analysis. The original manner of performance (21 Pilots) seems to be, in a way, 'consistently unpredictable', since some choices regarding intonation could not be anticipated based on the lyrics alone, but can be explained as motivated by affective information to be communicated. The acoustic version by Tyler Joseph, in turn, could be described as not fully predictable but explicable, since the intonation patterns in the first stanza and the last chorus are not fully predictable based solely on the affective value (especially valence) communicated in the lyrics. Yet, these 'deviations' are not unmotivated and can be attributed to the overall pattern of the stanza (first stanza) or a focus on arousal rather than valence, or signaling different metaphors.

\section{The analysis: Here Comes the Night Time by Arcade Fire}

\subsection{The lyrics}

The musical component and the manner of vocal performance also play a salient role in modifying the emotional potential of the lyrics, or rather in correlating not the most typical pattern of affect with the textual component in the song Here Comes the Night Time. The speaker in the lyrics talks about missionaries or preachers whose teachings are motivated by the common DARKNESS/LIGHT and OUTSIDE/INSIDE conceptual schemata with a typical pattern of affect ascribed to these schemata, i.e. the aim is to invoke the metaphorical contrasting pairs NEGATIVE/PAGAN IS DARK - POSITIVE/ RELIGIOUS IS LIGHT and NEGATIVE IS OUTSIDE - POSITIVE IS INSIDE (cf. Arcade Fire 2013; also see: Arcade Fire 2018). Therefore, they tell people to "head inside" (Arcade Fire 2013) when it gets dark, "when the sun goes down" (Arcade Fire 2013), otherwise the late-comers "will be left behind" (Arcade Fire 2013), so "If you want to be righteous, get in line" (Arcade Fire 2013). Consequently, falling intonation and relatively low pitch may be anticipated for the entire stanza, except possibly for the part "you don't mind", 
if the value of valence is to be reflected in vocal realization and music. The falling intonation and low pitch should also pertain to the line "Here comes the night time", which is repeated three times in the stanza, and the chorus consisting of the lines: "Cause here comes the night time / Here comes the night time (x 4) / Here comes the night / Here comes the night time / Look out, here comes the night time" (Arcade Fire 2013).

In the second stanza, the missionaries are said to condemn music and place it outside heaven: “They say, heaven's a place / Yeah, heaven's a place and they know where it is / It's behind the gate, they won't let you in / And when they hear the beat, coming from the street, they lock the door" (Arcade Fire 2013). The speaker contests this idea saying, "But if there's no music up in heaven, then what's it for? / When I hear the beat, my spirit's on me like a live-wire / A thousand horses running wild in a city on fire" (Arcade Fire 2013). Therefore, falling intonation could be expected for the lines describing the preachers' views, and rising intonation would be a plausible match for the expression of the speaker's views and attitude to music. In this way, the usual valence ascribed to the concepts of INSIDE and OUTSIDE seems indirectly modified by expressing the desire to stay outside where positively valued music is situated. In the line: "But it starts in your feet, then it goes to your head" (Arcade Fire 2013) rising intonation may be expected in accordance with the embodied experience. For the penultimate line of the stanza, either falling intonation (NEGATIVE IS DOWN) owing to the phrase "then the roots are dead" (Arcade Fire 2013) is likely to be applied or non-final intonation since the end of the line does not coincide with the end of the sentence. The question "what is our crime?" (Arcade Fire 2013) in the ultimate line, if affectively unmarked, should be sung with falling intonation. The speaker may, however, wish to express irritation, frustration or use an accusatory tone, and hence use rising intonation.

In the context of the speaker's views presented in the second stanza, the following chorus consisting of the lines "Here comes the night time", "Look out, here comes the night time!" and "Here comes the night!" (Arcade Fire 2013) repeated several times is likely to be performed with rising intonation, possibly accompanied with music of a relatively high pitch and fast tempo, especially as they seem to imply high arousal connected with dancing and partying. With regard to the bridge, the choice of either of the two divergent intonations seems plausible. The line about the preachers talking "Up on the satellite" (Arcade Fire 2013) could be sung with rising intonation owing to the preposition used. If the speaker's evaluation of the preachers' views is considered, however, such choice seems highly unlikely, and falling intonation can be anticipated. By the same token, for the line: "If you're looking for hell, just try looking inside" (Arcade Fire 2013), due to the mental link of INSIDE with hell, falling intonation seems a natural choice, even though in accordance with the INSIDE/OUTSIDE conceptual schema, INSIDE commonly carries a positive axiological default. The intonation/music accompanying the closing lines: "When you look in the sky, just try looking inside / God 
knows what you might find" (Arcade Fire 2013) is somewhat more difficult to anticipate. Though mentioning the sky commonly evokes the metaphor POSITIVE IS UP, just as the notion of INSIDE (in contrast to OUTSIDE), the INSIDE has already been linked to hell in the previous line. What can actually be found there is, as expressed in the last line, not predetermined.

\subsection{The performance}

The piece starts with a relatively long instrumental intro that appears to metonymically activate a mental scenario of dancing, possibly a party. The music can be described as energetic, with a fast tempo and ascending musical sequences. Shortly before the verbal part begins, the tempo slows down, and punctual 'inserts' of low, disturbing sounds appear. The low, disturbing sounds accompany the words down and inside in the initial lines: "When the sound goes down / When the sun goes down you head inside" (Arcade Fire 2013), as well as the lexeme righteous in: "If you want to be righteous / If you want to be righteous, get in line" (Arcade Fire 2013) where the disturbing sounds are even lower, thus apparently communicating a negative valence attached to these items in accordance with the NEGATIVE IS DOWN metaphor. Negative valence is also signalled by the falling intonation used throughout the whole first stanza, except for the line "Here comes the night time" (Arcade Fire 2013), which is repeated three times with non-final intonation. Additional portions of soft, high-pitch music are added to this line, which may be interpreted as a kind of foreboding of positive valence and high arousal to be voiced later in the song.

The speaker's negative attitude towards the views of the missionaries voiced in the second stanza is also reflected at the musical level. In the second stanza, for the lines describing the preachers' views and for the expression of the speaker's views and attitude to music, falling intonation and rising intonation are employed as expected, respectively. Only for the line "But it starts in your feet, then it goes to your head" (Arcade Fire 2013) and the next one containing the phrase the roots are dead (Arcade Fire 2013), non-final intonation instead of the predicted rising and falling, respectively, is used. The question "what is our crime?" (Arcade Fire 2013) in the ultimate line proves to be affectively marked, as it is sung with rising intonation (accusatory tone, maybe frustration).

The chorus is, each time, first preceded and then sung accompanied by ascending high-pitch musical sequences. The tempo of the song accelerates significantly at the end of the second chorus and remains fast for the bridge, which is, as predicted, performed with falling intonation and slows down again for the lines: "When you look in the sky, just try looking inside / God knows what you might find” (Arcade Fire 2013). The former is performed with rising intonation for both sentence parts, while for the latter, non-final intonation is selected. Both lines are accompanied by relatively high pitch music but with a slower tempo. 
The intonation/pitch patterns and changes of tempo in the song clearly indicate high arousal connected with dancing and may invoke positive valence concerning the night time, even though DARKNESS is commonly associated conceptually and affectively with NEGATIVE, which corroborates Sopory's observations (cf. 2005: 442) about experiential knowledge of the events or processes talked about, which can override typical patterns of valence ascribed to orientational metaphors. If we look at Kim and Andre's (2008: 5) Fig. 2, we notice that relatively high pitch but slower tempo in the last lines may indicate a fall in arousal with a possible simultaneous shift towards negative valence.

\section{The analysis: Die Flut [the deluge]}

\subsection{The lyrics}

In the textual component of the song, the stanzas contain lexemes invoking the DARKNESS/LIGHT schema and the typical pattern of affect attributed to these phenomena, reinforced with other emotionally laden lexemes to express the speaker's depressive mood, possibly his disillusionment concerning the surrounding reality. Metaphorical mappings from the FOOD and TEMPERATURE domains onto the domain of EMOTIONS seem to be exploited as well, i.e. NEGATIVE EMOTIONS AS UNTASTY/BITTER FOOD or NEGATIVE IS COLD: "Bitterkeit mein dunkles Herz umspült (...) Wenn Finsternis den klaren Blick verhüllt / Kein Sinn mehr eine Sehnsucht stillt” [Bitterness washes around my dark heart (...) When darkness blocks the clear view / No sense quenches the longing anymore] (Heppner 2018) and in the second stanza: "Gibt es dort am kalten Firmament / Nicht auch den Stern (...) / Ein dumpfes Leuchten, wie ein Feuer in der Nacht" [Is there in the cold sky / no star (...) A dull glow, like fire in the night] [all translations and emphasis mine] (Heppner 2018). The last line is about a dream that will never materialize: "Ruf ich mir herbei ein Traum / Der sich niemals erfüllt" [I summon a dream / which never materializes] (Heppner 2018). Consequently, falling intonation may be expected for the whole two stanzas as well as music with a slow tempo and of low key. In the bridge - in its three variations - a wish for a new, better world is expressed, which is never to be fulfilled: "Doch es wird keine andere geben (or "Doch es wird keine andere sein") [but there will be no other] (Heppner 2018). Here again, the negative emotional potential of the lyrics would correspond well with falling intonation / low key, maybe except for the lines: "Und du siehst zum Himmel auf" [And you look up to the sky] and "Du willst eine schönere erleben" [You want to experience a more beautiful one] (Heppner 2018) where, in accordance with the embodied experience and affective value, rising intonation is also a viable option. In the chorus, however, the speaker clearly reverses the affective value typically ascribed to the phenomenon designated by the lexeme die Flut 'the deluge' by conceiving of it as washing away all the evil that he sees on earth as a force able to transport him into better life (cf. Heppner 2018). 
This part consists of the question "Wann kommt die Flut" [When will the deluge come] (Heppner 2018), which is to be sung four times, each time complemented by the parts: "über mich" [wash around me], "die mich berührt" [that will touch me], "die mich fortnimmt [that will take me]" (Heppner 2018) and concluded: "In ein anderes großes Leben irgendwo" [into a different, bigger life somewhere] (Heppner 2018). The standard neutral intonation for suppletive questions and statements in German is the falling one, though it seems that the positive aspect of the emotional potential is activated here by invoking the metaphor SPIRITUAL/MORAL CLEANSING IS PHYSICAL CLEANSING BY WATER, and hence application of rising intonation also seems plausible.

\subsection{The performance}

The German piece performed by Joachim Witt and Peter Heppner, similarly to Ride, involves intentional changes in pitch and intonation and alternate high and low keys (and two different voices). In terms of music, the song opening guides the recipient's anticipation regarding affective information to be communicated as the song starts with a slow tempo and low key intro, which seems to metonymically forebode the pessimistic aspect of the emotional potential. The choice of key, pitch patterns and tempo with respect to the music clearly correspond with the intended affective information communicated by the text of the song. The stanzas are sung slowly in a low voice by Joachim Witt, accompanied by low-key music with a slow tempo. The intonation is non-final for all the verses except for the last, where falling intonation is applied. This seems to result not only from the standard intonation patterns for sentences in German but also that the first stanza harmonizes with the emotional potential activated in the text. The bridge, in turn, is sung by Peter Heppner in a higher voice, and the tempo is faster. The intonation for all the lines except for the last is falling, which is in accordance with the afore-described predictions. The line closing the bridge, however, in which the speaker states that there will be no new, better world, is sung louder with rising intonation. The affective information in this case attached to the VERTICALITY schema seems to be concerning high arousal rather than positive valence and may possibly be aimed to invoke the metaphor IMPORTANT IS UP, correlated with IMPORTANCE IS VOLUME (entailing MORE IMPORTANT IS LOUDER). The question in the chorus "Wann kommt die Flut" [When will the deluge come] (Heppner 2018) is performed (four times) by both vocalists alternately (i.e. in low and high voice) with rising intonation (especially when performed at the end of the piece), whereby Heppner's voice rises on the stressed word kommt, while Witt's voice rises on the stressed Flut. The second part of each question is sung by Witt alone with non-final intonation, probably because the text still continues. The final chorus line: "In ein anderes großes Leben irgendwo" [into a different, bigger life somewhere] (Heppner 2018) is performed by both Witt and Heppner simultaneously with rising intonation up to "Leben", then falling with 
the lexeme irgendwo. Such intonation pattern is clearly affectively marked, since the standard neutral intonation for suppletive questions and statements in German is the falling one. The rising intonation here in the context of the whole song seems to indicate not only high arousal but positive valence (metaphorically identifiable as POSITIVE IS UP), since the positive aspect of the deluge is emphasised. Note that even though Witt's voice is a low one, in the chorus he adopts a noticeably higher key. Rising intonation and high pitch may, furthermore, serve to evoke the metaphor HAVING FORCE IS UP (cf. Górska 2014: 182) concerning the phenomenon of a deluge.

\section{Conclusions}

The analysis of the research material reveals the salient presence of the UP/DOWN (=VERTICALITY) image schema in vocal intonation and music aimed to enhance or modify emotional potential at the verbal level. The song performers employ changes in vocal intonation, combinations of alternate high and low pitch, slow and quick tempo and ascending and descending melodic lines to evoke certain metaphors and metonymies. There are cases, as noticed by Sopory (cf. 2005: 442) and in Hampe's (2005) analysis, where the pattern of affect typically associated with the VERTICALITY image schema in vocal intonation and accompanying music may seem not to match the valence pattern typically available in the form of the metaphors POSITIVE IS UP and NEGATIVE IS DOWN expressed in a given piece of lyrics. It appears, however, that the seemingly non-typical patterns of affect identified in the material examined herein (e.g. positive valence ascribed to darkness or deluge, high pitch not connected with positive valence) can, more often than not, be predicted on the basis of a thorough analysis of lyrics if the experiential knowledge available to the recipient of the phenomena/events referred to in the textual component is considered. It does not, for instance, suffice to identify the DARKNESS/LIGHT or OUTSIDE/INSIDE image schemata at the verbal level and to assume that in accordance with the default value of valence ascribed to them, the intonation should be falling or rising, respectively. The whole context, that is the night time as the time for the speaker to party (as in Here Comes the Night Time), should be taken into account. This means including the aspect of arousal or reference to other metaphors, for example IMPORTANCE IS VOLUME, in the analysis. In some cases, only one, not the most typical but rather latently present, aspect of emotional potential (negative or positive) inherent in a given song may be actualized, such as the cleansing potential of the deluge rather than its destructive force. Eventually, certain manners of vocal realization may result from the adopted intra-opus pattern of the song (e.g. acoustic version of Ride). 


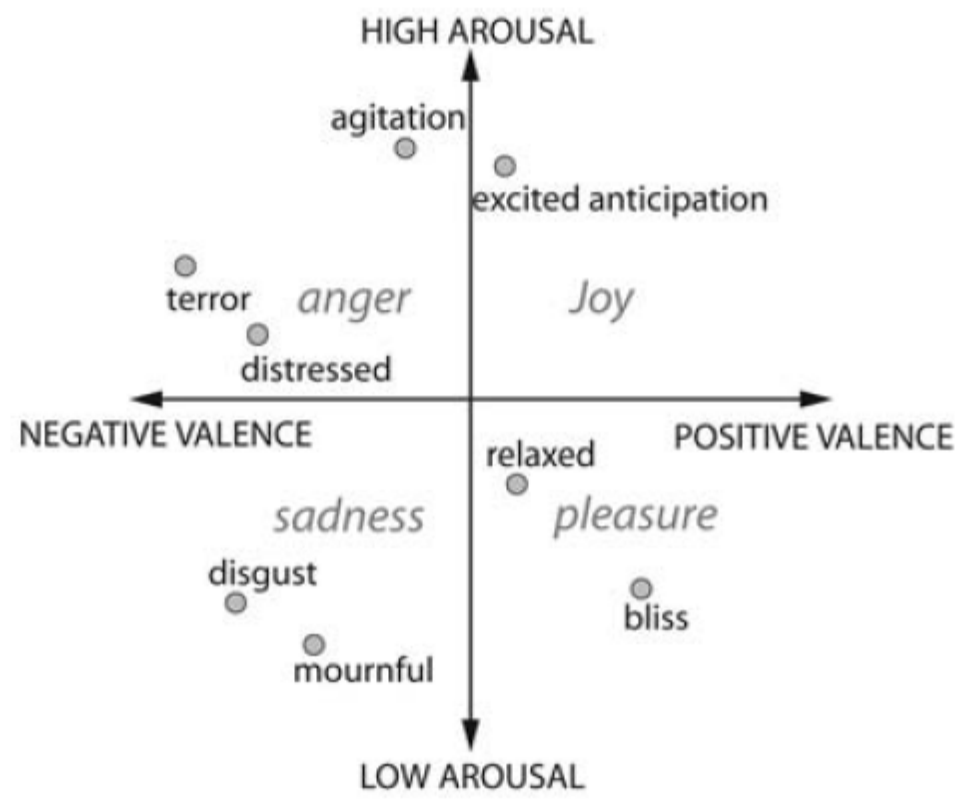

(a)

Fig. 1. Two-dimensional emotion model by valence and arousal (Kim \& Andre 2008, 4).

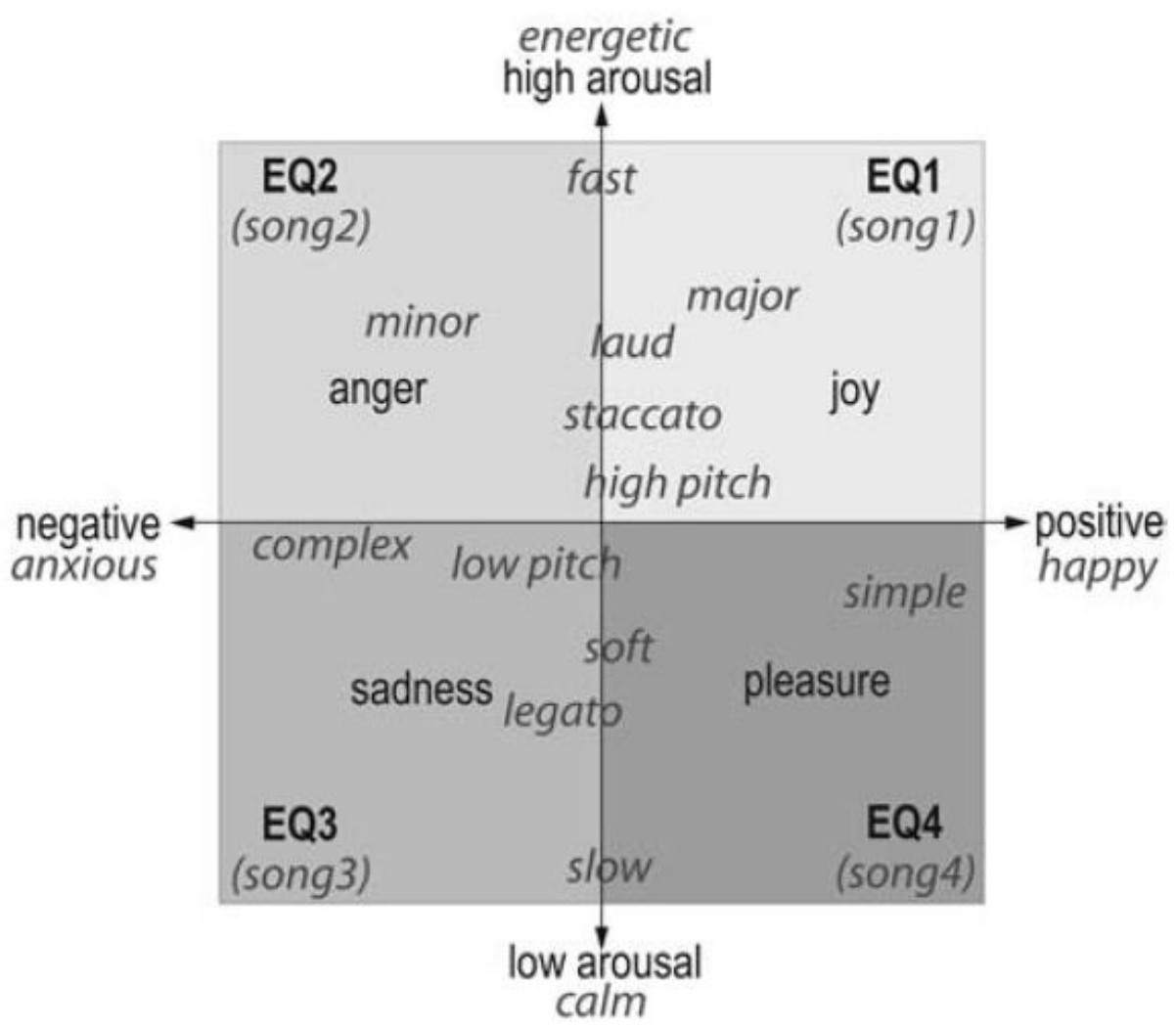

Fig. 2. Reference emotional cues in music based on the $2 \mathrm{D}$ emotion model. EQ1 = positive/high arousal, EQ2 = negative/high arousal\}, $\mathrm{EQ3}=$ negative/low arousal, and EQ4 = positive/low arousal.

(Kim \& Andre 2008, 5) 


\section{References}

Arcade Fire. 2013. Here comes the night time. In: Arcade Fire, Reflektor. EMI Music Ltd.

Arcade Fire. 2018, November 25. Here Comes the Night Time [Video]. YouTube. https://www. youtube.com/watch?v=FOTAu@Xq5X8 (1 January 2019).

BBC Radio 1. 2018, November 1. Tyler from Twenty One Pilots - Ride in the Live Lounge [Video]. YouTube. https://www.youtube.com/watch?v=A7Cbd1wU8TA (1 January 2019)

Górska, E. 2014. The UP/DOWN orientation in language and music. In: M. Brenzinger \& I. Kraska-Szlenk (eds.), The Body in Language. Comparative Studies of Linguistic Embodiment, 177-195. Leiden: Brill (Brill's Studies in Language, Cognition and Culture, 8).

Hampe, B. 2005. When down is not bad, and up is not good enough: A usage-based assessment of the plus-minus parameter in image-schema theory. Cognitive Linguistics 16(1): 115-146.

Heppner, P. [Peter Heppner]. 2018, April 16. Witt-Heppner - Die Flut [Video]. YouTube. https://www.youtube.com/watch?v=jVnmusVr_NI (1 January 2019).

Juslin, P. N. \& Sloboda, J. A. 2010. Handbook of Music and Emotion: Theory, Research, Applications. Oxford: Oxford University Press.

Kim, J. \& Andre, E. 2008. Emotion recognition based on physiological changes in music listening. IEEE Transactions on Pattern Analysis 30(12): 1-17.

Kövecses, Z. 1990. Emotion Concepts. New York: Springer-Verlag.

Krzeszowski, T. P. 1997. Angels and Devils in Hell: Elements of Axiology in Semantics. Warsaw: Wydawnictwo Energeia.

Lewandowska-Tomaszczyk, B. \& Hanks, P. 1996. Completive particles and verbs of closing in English. In: E. Weigand \& F. Hundsnurscher (eds.), Lexical Structure and Language Use. Proceedings of the International Conference on Lexicology and Lexical Semantics, Münster, September 13-15, 1994, 89-103. Tübingen: Niemeyer.

Morini, M. 2013. Towards a musical stylistics: Movement in Kate Bush's 'Running Up That Hill'. Language and Literature 22(4): 283-297.

Neary, C. 2019. 'Please could you stop the noise': The grammar of multimodal meaning-making in Radiohead's 'Paranoid Android'. Language and Literature: International Journal of Stylistics 28(1): 41-60.

NOVA FM. 2016, September 4. Pentatonix cover 'Ride' by Twenty One Pilots [Video]. YouTube. https://www.youtube.com/watch?v=fdqBqIpuJLs_(1 January 2019).

Schwarz-Friesel, M. 2007. Sprache und Emotion. Tübingen: Francke.

Schwarz-Friesel, M. 2015. Giving horror a name: Verbal manifestations of despair, fear and anxiety in texts of Holocaust victims and survivors. In: U. M. Lüdtke (ed.), Emotion in Language. Theory - Research - Application, 289-304. Amsterdam/Philadelphia: John Benjamins. 
Schwarz-Friesel, M. 2015. Language and emotion: The cognitive linguistic perspective. In: U. M. Lüdtke (ed.) Emotion in Language. Theory - Research -Application, 157-174. Amsterdam/Philadelphia: John Benjamins.

Shrivastav, R. \& Wingate, J. (2008). Perceptual attributes and assessment of the singer's voice. In: M. S. Benninger \& T. Murry (eds.), The Singer's Voice, 65-78. San Diego/ Oxford/Brisbane: Plural Publishing.

Sopory, P. 2005. Metaphor and affect. Poetics Today 26(3): 433-458.

twenty one pilots 2015, May 13. twenty one pilots - Ride (Official Video) [Video]. YouTube. https://www.youtube.com/watch?v=Pw-@pbY9JeU (1 January 2019).

Zbikowski, L. 2009. Music, language, and multimodal metaphor. In: Ch. J. Forceville \& E. Urios-Aparisi (eds.), Multimodal Metaphor, 359-381. Berlin: Mouton de Gruyter. Zbikowski, L. 2017a. Foundations of Musical Grammar. Oxford: Oxford University Press. Zbikowski, L. 2017b. Music, analogy, and metaphor. In R. Ashley \& R. Timmers (eds.), The Routledge Companion to Music Cognition, 501-512. New York/London: Routledge.

Zbikowski, L. 2018. Music, metaphor, and creativity. https://www.researchgate.net/ publication/326904557_Music_Metaphor_and_Creativity_DOI：10.13140/RG.2.2.10878.08004 (1 March 2019).

Magdalena Zyga, $\mathrm{PhD}$, is an adjunct professor at the University of Szczecin (Institute of Linguistics). Her research interests encompass translation studies, especially literary translation, cognitive linguistics and discourse analysis. In 2012, she obtained her doctorate on the basis of the dissertation Idiolekte in deutschsprachigen literarischen Texten [Idiolects in German-language literary texts], published in 2013. 